DATA DE

RECEPCIÓN:

$25 / 06 / 2018$

DATA DE

ACEPTACIÓN:

$10 / 09 / 2018$

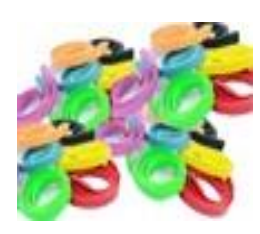

\section{AS SOMBRAS DO CARDUME: A GUERRA CIVIL NA MEMORIA INTERXERACIONAL}

\author{
LAS SOMBRAS DEL CARDUME: \\ LA GUERRA CIVIL EN LA MEMORIA INTERGENERACIONAL
}

\author{
SHOAL SHADOWS:THE SPANISH CIVIL WAR \\ INTHE INTERGENERATIONAL MEMORY
}

\author{
Irene Pin Basanta \\ Universidade de Santiago de Compostela \\ irene.bpin@gmail.com
}

\begin{abstract}
Resumo: O obxectivo deste traballo, no marco da literatura comparada, consiste na análise de dúas obras que tratan a temática da guerra civil en Galiza desde a perspectiva da recuperación da memoria por parte dunha xeración que non viviu directamente os feitos. Porén, a pegada do conflito chega ata eles e pon en foco a necesidade de repensar a relación co pasado. Cada un destes traballos pertence a un sistema literario diferente: Noite de Voraces Sombras (Agustín Fernández Paz, 2002) forma parte da literatura infantil e xuvenil, mentres Cardume (Rexina Vega, 2007) é literatura para adultos. Deste xeito, repararase nos puntos de conexión e nos temas comúns das dúas novelas, así como nas diferenzas principalmente motivadas pola súa concepción para distintos públicos. En calquera caso, a súa existencia sumada ao amplo corpus que trata o tema chama a atención sobre a necesidade social manifestada polos autores por establecer marcos de relación, fundamentalmente desde unha óptica familiar, dun conflito que debido aos procesos históricos de transformación postfranquistas non acadaron unha resolución para as vítimas.
\end{abstract}

Palabras chave: Guerra Civil, Memoria, Agustín Fernández Paz, Rexina Vega.

Resumen: El objetivo de este trabajo, en el marco de la Literatura Comparada, consiste en el análisis de dos obras que tratan la temática de la Guerra Civil en Galicia desde la perspectiva de la recuperación de la memoria por parte de una generación que no ha vivido directamente los hechos. Sin embargo, la huella del conflicto llega hasta ella y pone de manifiesto la necesidad de repensar la relación con el pasado. Cada una de estas obras pertenece a un sistema literario diferente: Cardume (Cardumen, Rexina Vega, 2007) es literatura para adultos, mientras Noite de Voraces Sombras (Noche de Voraces Sombras, Agustín Fernández Paz, 2002) forma parte de la literatura infantil y juvenil. De esta forma, se reparará en los puntos de conexión y en los temas comunes a las dos novelas, así como en las diferencias principalmente motivadas por su concepción para diferentes públicos. En cualquier caso, su existencia sumada al amplio corpus que trata el tema en la literatura gallega contemporánea llama la atención sobre la necesidad social manifestada por los autores por establecer marcos de relación, fundamentalmente desde una óptica familiar, con un conflicto que debido a los procesos históricos de transformación postfranquistas no consiguieron una resolución para las víctimas.

Palabras llave: Guerra Civil, Memoria, Agustín Fernández Paz, Rexina Vega.

Abstract: The objective of this article, concerning the field of Comparative Literature, is to analyse two works that deal with the topic of Spanish Civil War in Galicia from the perspective of the memory recovery by a new generation that has not directed been involved in the facts. But still, the trace of the war remains present to them and claims for the need to rethink the relation to the past. Each one of this two works belongs to a different literary system: Cardume (Shoal, Rexina Vega, 2007) is for adults, while Noite de Voraces Sombras (Night of Voracious Shadows, Agustín Fernández Paz, 2002) was written to young ones. In this way, it will be notice the points of connection and the common topics of this two novels, as well as the differences according to the audience they were conceived for. Regardless, their simple existence in addition to the wide range of works dealing with the topic in contemporary Galician Literature stands out the social claim for establishing new frameworks of relationship, from a familial point of view fundamentally, with a conflict that is not resolved for the victims, as the historical posfranquist process of transformation were not conceived in order to do it.

Keywords: Spanish Civil War, Memory, Agustín Fernández Paz, Rexina Vega.

Pin Basanta, Irene (2020).

"As sombras do Cardume: a guerra civil na memoria interxeracional". Elos. Revista de Literatura Infantil e Xuvenil, 7, "Notas", 19 36. ISSN 2386 7620. DOI http://dx.doi.org/10.15304/elos.7.5203 


\section{Irene Pin Basanta}

\section{Introdución}

Cando Rexina Vega gañaba o Premio Xerais de Novela en 2007 con Cardume, declaraba: “Outra maldita novela sobre a Guerra Civil? Eu non quería facer unha novela sobre a Guerra Civil, quería reescribir a miña memoria. Evidentemente, o conflito non está pechado, e agora tócanos aos netos eliminar as zonas de sombra" (Iglesias, 2007). Estas palabras denotan, entre outras cousas, certa saturación na recepción social dos discursos sobre este conflito, así como a pertenza da autora a unha terceira xeración coa necesidade de recuperalo como punto de encontro interxeracional. Como afirma Nieves Martín Rogero (2008: 49-50) “con la llegada del nuevo siglo la guerra y la posguerra vuelven a recuperar terreno dentro de la producción histórica, en consonancia con el intento de recuperación de la memoria histórica que afecta al sistema semiótico general de la cultura”. Esta resurrección literaria enténdese como un acto de reparación, na medida en que fai visibles episodios e personaxes que doutro xeito quedarían sepultados (Vilavedra, 2011a: 7). Esta tendencia maniféstase tamén na Literatura Infantil e Xuvenil galega, trala serodia introdución do tema na década dos noventa (Roig, 2008: 73) e a súa consolidación nos 2000. Agustín Fernández Paz é un dos escritores que máis o ten abordado, chegando a situarse no canon con libros como Noite de Voraces Sombras (2002), obra pioneira pola profundidade do seu tratamento dunha tópica até daquela pouco transitada (Soto, 2008: 253).

O obxecto deste traballo é comparar estas dúas obras, Noite de Voraces Sombras (en diante, NVS) e Cardume, construídas sobre a memoria por unha terceira xeración que procura a súa forma de relacionarse cuns feitos pasados traumáticos, sepultados nunha amnistía asentada sobre a amnesia colectiva. En ambas a Guerra Civil aparece como marco que condiciona irremediablemente as vidas das personaxes, logo dese breve remanso de ilusións da II República. Porén, verase como alén de puntos de conexión espaciais e temáticos, algunhas das diferenzas se atopan especialmente marcadas pola súa pertenza a sistemas literarios diferentes.

NVS narra a historia de Sara, unha adolescente da Coruña que vai pasar o mes de agosto a Viveiro coa súa familia. Alí, alén de experimentar a paixón dun amor de verán con Daniel, descobre a historia esquecida do seu tío Moncho, un mestre encarcerado durante a Guerra Civil. O achado do seu diario e das cartas da súa namorada, a tamén mestra Sara Salgueiro, levará a Sara a emprender unha viaxe á Illa de San Simón para recuperar o anel agochado do seu tío e restaurar a súa memoria.

A acción principal de Cardume transcorre durante o primeiro terzo do século $\mathrm{XX}$, nun Vigo British asemade cosmopolita, industrial e provinciano. Nunha reflexión sobre a permanencia 


\section{As sombras do Cardume: a guerra civil na memoria interxeracional}

interxeracional da memoria, seguindo o seu propio fío familiar, a nena narradora relata unha serie de traxectorias vitais xa escritas. Nelas, a guerra maniféstase como paisaxe, obrigando a reaccionar ás personaxes. O tío Fasito, dandi gigoló, crítico de espectáculos e pequeno empresario fracasado, acabará traballando en Nova York, desentendéndose da contenda. Dámaso, señorito sedutor, primeiro amor da avoa, farase líder local da Falanxe. Urbano R. Moledo, dramaturgo galeguista que existiu realmente, será fusilado a pesar dos esforzos da avoa e o avó. Ela, señorita de familia burguesa vida a menos, loitará por salvar o seu curmán da morte. El, emigrante retornado, policía numerario da garda armada, axudaralle contra a súa natureza mansa de non significarse.

NVS inclúese dentro do denominado "ciclo das sombras" ou "triloxía da memoria", xunto "As sombras do Faro" (2004) e Corredores de Sombra (2006), incidindo no elemento repetido como símbolo dos mortos na Guerra Civil e do escurantismo que rodea a súa memoria. Os paratextos autorais afianzan este significado nun título que, como ben indica Isabel Soto (2008: 255), funciona como metatexo, fornecendo unha clave de lectura da novela e contribuíndo "á súa coherencia interna ao metaforizar os límites espazo-temporais evocados pola diéxese, ao tempo que funciona como unidade significativa autónoma de alto valor poético”. A presenza no limiar dos versos de Fragmentos de un libro futuro de José Ángel Valente, que dan nome á obra, completa este sentido de recuperación dos anacos do pasado perdidos que será misión de Sara:

\footnotetext{
De ti no quedan más

que estos fragmentos rotos.

Que alguien los recoja con amor, te deseo,

los tenga junto a sí y no los deje

totalmente morir en esta noche

de voraces sombras donde tú ya indefenso

todavía palpitas. (Fernández Paz, 2002: 6).
}

${ }^{1}$ Relato recollido no libro Tres pasos polo misterio (Fernández Paz, 2004) 


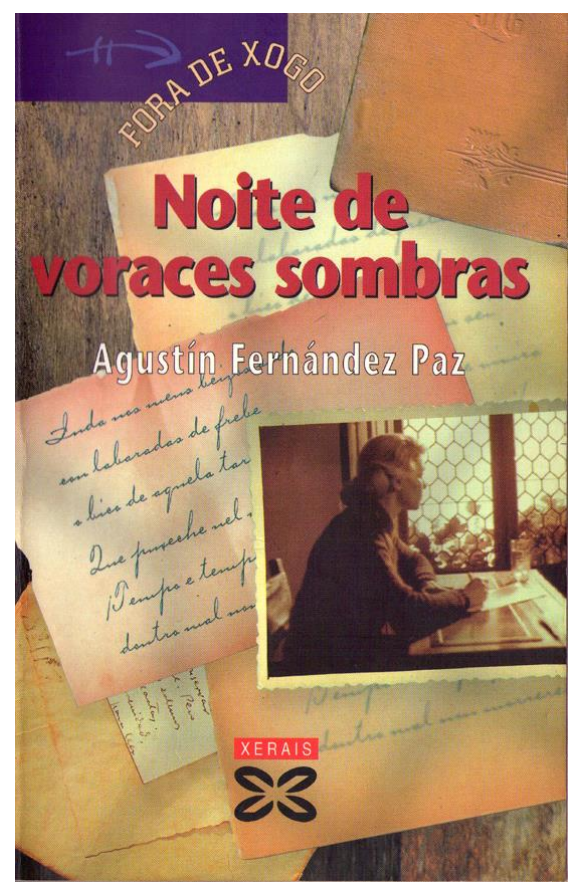

Imaxe 1

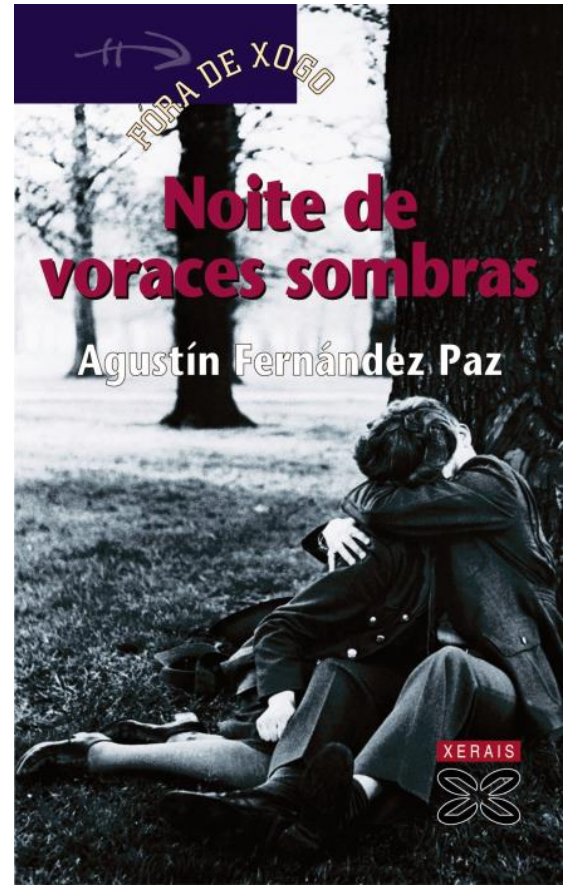

Imaxe 2

Así, como indica Agrelo Costas (2015: 339), a obra descansa na "necesidade de recompoñer a memoria de vida dun mestre republicano duramente castigado, a través da cal tamén recuperar a memoria e dignidade daqueles que foron maltratados e acalados por seren defensores dunha ideoloxía contraria á franquista". No mesmo sentido opera a portada das primeiras edicións (Imaxe 1), anticipando o valor dos documentos na relación co pasado por parte das novas xeracións, mentres as reedicións máis actuais (Imaxe 2) inciden no aspecto máis romántico da historia dos mestres, aínda que mantendo o toque nostálxico de alusión a un tempo anterior mediante o uso da fotografía en branco e negro.

De maneira análoga, Rexina Vega evoca cos versos de Jorge Luís Borges a liberación que traerá a morte, achegándose ao conflito da memoria dos desaparecidos:

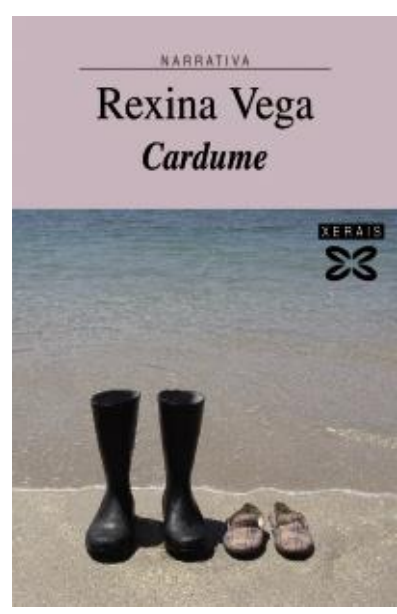

O alivio que ti e mais eu sentiremos no intre que precede á morte, cando a sorte nos desate do triste costume de ser alguén e do peso do Universo. (Vega, 2007: 7) 


\section{As sombras do Cardume: a guerra civil na memoria interxeracional}

O uso desta cita introduce a temática da extinción da lembranza da guerra a medida que as súas testemuñas directas falecen. Isto trae a primeiro plano a cuestión da necesidade dunha concepción da memoria como algo interxeracional, que pervive a través do tempo no seu paso a través dos integrantes da institución familiar. Igual que NVS, a portada de Cardume alude, se ben de maneira mais abstracta, á desaparición das lembranzas dos ausentes mediante a conxugación en primeiro plano dos dous pares de zapatos baleiros fronte á ourela da praia (Imaxe 3), que evocan a permanencia do recordo como rastro deixado para os que fican aínda no mundo. Precisamente esta é unha das dimensións clave do sentimento que define a idea do cardume tal e como aparece na novela de Vega, chamando a atención sobre unha noción da humanidade máis alá da suma das súas individualidades. Así, a memoria interxeneracional permite que as vivencias dos mortos permanezan dalgún xeito no mundo, como parte daqueles que os amaron e de cuxas vidas aínda forman parte.

En relación a isto, cómpre considerar, como indica Dolores Vilavedra (2011b, 76), que ante o afastamento temporal do conflito da Guerra Civil "el tema se enfrenta a dos disyuntivas posibles: la ficcionalización total o (y esta no es incompatible con la anterior) su integración en el modelo genérico de la novela histórica”. Vega, aínda que partindo de feitos pertencentes á memoria familiar, elabora un relato ficcional dos sen nome nin voz na historia, masas esquecidas. Daqueles que apenas foron, refuxiados ou condenados no conxunto informe de moitas vidas. Urbano, preso, escribe: "sentimos intensamente o golpe do medo, axotándonos, aproximándonos. Convertémonos en cardume, e comezamos por iso mesmo, a chorar acompasado, baixo, grave, coa conciencia de sermos un en moitos corpos distintos" (Vega, 2007: 163). Ambos títulos presentan, polo tanto, unha metáfora do sentir das súas historias que as sitúa ademais no ámbito do común. Este sentido do colectivo lembra aqueles versos das Meditations de John Donne que abrían a novela de Ernest Hemingway For Whom the Bell Tolls (1940), nos que o autor refire "the motto of a man trying to retain a sense of interconnectedness in his world" (Hillman, 2015: 44):

No man is an Iland, intire of it selfe; every man is a peece of the Continent, a part of the maine; if a Clod bee washed away by the Sea, Europe is the lesse, as well as if a Promontorie were, as well as if a Mannor of thy friends or of thine owne were; any mans death diminishes me, because I am involved in Mankinde; And therefore never send to know for whom the bell tolls; It tolls for thee. (Hemingway, 1984: 5) 


\section{Irene Pin Basanta}

Neste sentido da existencia interconectada que aparece de maneira evidente en Cardume e de xeito máis tanxencial e vinculada ao seo familiar en NVS, cada persoa, ligada á humanidade, vese afectada polo destino dos demais. Esta referencia, rescatada nunha das obras emblemáticas a nivel internacional sobre o conflito bélico español, dá conta do idealismo presente no discurso bélico coetáneo, que chega en certo modo aos nosos días. Pero a perspectiva de Hemingway, testemuña directa e participante na contenda, non se corresponde coa que ocupa este traballo, baseado na Guerra Civil como relato dentro do universo familiar, rastrexando a profunda pegada deixada sen resolver que converte a súa representación literaria nun obxecto de estudo amplamente interesante e sobre o que convén seguir reflexionando.

\section{A Guerra Civil como memoria familiar}

Como en moitas narracións sobre o pasado, o detonante de NVS é a aparición de cartas ou obxectos persoais dun morto, técnica habitual tanto na literatura como no cinema. Atopámola, de feito, nun dos filmes máis aclamados a nivel internacional sobre a guerra civil española: Land and Freedom (Ken Loach, 1995), onde tamén é unha terceira xeración a encargada de recuperar uns feitos soterrados na memoria familiar. Esta historia ponse en marcha trala morte de David Carr, cando a súa neta atopa as cartas, fotos e outros obxectos persoais que inician un flashback das vivencias deste traballador comunista de Liverpool que loitou como voluntario na Guerra Civil Española. Igualmente, Sara atopa os libros e documentos do seu tío ao durmir no seu cuarto, orixinando así unha "conxunción de voces múltiples en primeira persoa e provenientes de diferentes soportes textuais" (Agrelo Costas, 2015: 545). A adolescente séntese abraiada ao comprobar como a vitalidade das palabras lle chega intacta a través dos anos (Fernández Paz, 2002: 75), igual que cando en Cardume se afirma que o lido “vive e está pasando a un tempo" (Vega, 2007: 56). Esta función é outorgada tamén ás fotografías no relato, capaces de cumprir esa necesidade humana primixenia, presente na invención da cámara, de vencer a morte, embalsamando, como diría Bazin, o tempo (1990: 29).

Aínda que os documentos tamén teñen unha relevancia maiúscula en Cardume, o punto de partida non é o seu achado, senón a ritual visita ao cemiterio no día de Todos os Santos que a nena narradora fai coa súa avoa. Afirma que alí pode contemplar a súa devanceira de nova, deitando caraveis vermellos sobre as foxas e berrando “¡Viva la República!” (Vega, 2007: 11), episodio que 


\section{As sombras do Cardume: a guerra civil na memoria interxeracional}

se revela ao final do libro como acto de insubmisión ante a morte de Urbano. Esta superposición temporal vólvese característica dunha novela imbricada na lembranza como mecanismo cognitivo, que traslada unha recreación dos procedementos mentais da narradora, insistindo asemade nunha certa simultaneidade do pasado no presente a través dos recordos. O procedemento, empregado de maneira recorrente, aparece de novo, por exemplo, cando a avoa se reúne coas súas vellas amigas e falan do pasado. Entón, a narradora describe como as ve transformarse nas rapazas dun retrato de grupo que conservan no salón: "Mentres as outras, os corpos vencidos, ficaban inmóbiles en segundo plano como carautas abandonadas, as mozas chegaban alegres levándome da man pola rúa do Príncipe nas tardes dos anos 30” (Vega, 2007: 23).

Ambas historias parten de mulleres que se achegan ao pasado desde o presente, pero de maneiras diferentes. En NVS trátase dunha narradora-protagonista, autodiexética e equisciente, cuxa voz en primeira persoa refire uns feitos que a transformaron profundamente. O uso dunha figura feminina concorda co compromiso que Fernández Paz manifesta na súa obra apostando constantemente por estas personaxes, converténdose como sinala Agrelo Costas (2015: 559) "nun caso insólito no panorama literario infantil e xuvenil galega”. A introdución dun capítulo inicial proléptico marca a narración, ateigada de anticipacións que contribuirán a crear suspense. Sara insiste en subliñar o extraordinario da súa experiencia como algo máis propio dos universos da literatura e o cinema, desmarcándose dos procedementos habituais do típico diario adolescente para crear complicidade co lector. Deste xeito, a historia amorosa entre ela e Daniel, a diferenza do que acontece en Corredores de sombra, é abandonada privilexiando esoutra relación frustrada entre Moncho e Sara Salgueiro, que Fernández Paz emprega para encarnar o horror da guerra. Neste sentido, pode emparentarse cunha das formulacións textuais da ferida bélica no cinema español de posguerra que, como apuntan Castro de Paz e Pena Pérez (2005), toma corpo arredor da perda do obxecto amoroso (encarnado por unha muller, asasinada, prohibida, desaparecida ou traidora) e a soidade e a melancolía (ou mesmo a loucura) resultantes. Estas poden lerse como metáforas dun país desolado, poboado de sombrías lembranzas, tal como aparece en La casa de la lluvia (Antonio Román, 1943), Barrio (Ladislao Vajda, 1947), La sirena negra (Carlos Serrano de Osma, 1947), La calle sin sol (Rafael Gil, 1948) ou Un hombre va por el camino (Mur Oti, 1949). Este mesmo esquema de representación do universo da posguerra, se ben adaptado a un público adolescente, aparece tamén en NVS, conectando asemade co rol doutras personaxes creadas polo propio Fernández Paz, como, por exemplo, Milena, a sobriña do protagonista de Non hai noite tan 


\section{Irene Pin Basanta}

longa. Esta personaxe convértese tamén na depositaria da historia da familia (Agrelo Costas, 2016: 21) a través da conversas co seu tío Gabriel quen, coas súas indagacións nas traumáticas desventuras do seu pai leva a cabo unha "reparación" do pasado, mentres que o futuro de Milena encarna a súa "superación” (Martínez, 2012: 10).

Rexina Vega tamén opta por unha narradora en primeira persoa, pero cunha relación máis problemática cos acontecementos. "Educada nas lembranzas de mozos de outrora" (Vega, 2007: 19), relata feitos que forman parte da memoria familiar, de maneira non necesariamente secuencial e ordenada, senón instintiva, emulando o fluír dos pensamentos. Participa na historia, sendo asemade superior a ela ao adquirir unha focalización interna múltiple, expresando sentimentos de personaxes que nin sequera chegou a coñecer. Defínese así unha narradora homodiexética-intradiexética, nun claro caso do que Pouillon (1970) definía como "visión con", xustificada no último capítulo mediante unha identificación do proceso de escritura como un acto de espiritismo:

\footnotetext{
Nunha estraña cerimonia de ouigha foron eles os que ditaron as miñas palabras, os que quixeron volver contar a súa historia sobrevivindo en min. Estou traspasada de fantasmas, como todos o estamos. Nesta eterna rolda de morte e nacemento imos marchando moi lentamente; eu só quixen prolongar un pouco máis a permanencia, atrasar o devalo destas vidas menores. Poida que así, ao volver adoptar una forma fugaz nas miñas liñas, eses que no cardume apenas foron, atoparan alegría; e poida, quizais, que o meu afán por recordalos sirva para volver tamén máis lenta a miña propia caída (Rexina Vega, 2007: 193).
}

Como NVS, a obra presenta unha función de restauración da memoria sepultada de vidas truncadas pola guerra. Porén, se o silencio arredor do tío Moncho é o que leva a Sara a embarcarse na investigación do misterio, en Cardume o interese da narradora parte dunha fascinación polos relatos do pasado que sentiu desde a infancia. A narradora chega a afirmar que con 12-13 anos estaba convencida de que se reencarnara nela o espírito dunha miliciana (Vega, 2007: 97). Igualmente, Rexina Vega admitía nunha entrevista que de nena soñaba con ser miliciana (Franco, 2007), marcando a forte carga autobiográfica no proceso de escritura afirmando: "deixeime posuír, como na ouigha. Conto a memoria do pasado para os meus familiares descendan” (Iglesias, 2007).

\section{Idealismo ou barbarie}

Como en moitas obras que tratan esta temática, ben pertenzan á LIX, como A lingua das bolboretas (Manuel Rivas, 2005) ou A teima de Xan (Antonio García Teijeiro, 2005), ben ao sistema 


\section{As sombras do Cardume: a guerra civil na memoria interxeracional}

adulto, como O lapis do Carpinteiro (Manuel Rivas, 1998) ou Agosto do 36 (Xosé Fernández Ferreiro, 1991), a esfera dos mestres ten un papel central en NVS. Nas súas cartas, Sara Salgueiro expresa o idealismo e a ilusión da Segunda República, da loita por un ensino sen medos nin imposicións e identifica as posibilidades da educación na transformación social do país: "Unha Galicia que acabe cos caciques que todo o controlan, unha terra de onde xa non haxa que emigrar, un país de homes e mulleres libres construíndo en liberdade o seu destino" (Fernández Paz, 2002: 73). Ademais, as referencias a persoeiros como Castelao, Peña Novo ou Casares Quiroga, así como a pertenza ás Irmandades da Fala, ligan os dous amantes á militancia galeguista da época. Nisto, enlaza con outros textos de Fernández Paz, entre eles os xa mencionados como pertencentes ao ciclo das sombras, nos que se observan "moitos trazos identitarios arredor da memoria, a través de referencias culturais e citas, tanto literarias como musicais, que deixan patente a existencia de dous bandos de carácter irreconciliábel con proxectos antagónicos: os que aman a lectura e as súas orixes e os que están a carón da barbarie" (Roig Rechou, 2008: 82).

Fronte á figura do mestre, en Cardume a represión será exercida contra un dramaturgo, personaxe que introduce unha crítica do precario sistema nacional de teatro da época. Consciente da súa mediocridade, Urbano ve constantemente mal interpretada a "denuncia histórica" presente na súa obra "dun pobo sometido, asoballado, esganado polas rendas e os caciques, e a pantasma da emigración ameazando os mellores homes [...]. Podía parecer unha historia de amor pero era a conciencia dolorosa dos campesiños e dos mariñeiros, un problema de clase, de país, de lingua (Vega, 2007: 28). Mais aínda así compartirá cos mestres a acusación de separatista, delito abondo, como se lamenta Sara Salgueiro, para que as súas vidas non vallan nada (Fernández Paz, 2002: 76).

A obra de Fernández Paz aglutina toda unha serie de informacións relativas á represión na retagarda galega, presentada nas cartas de Sara Salgueiro a partir de xullo do 36. A mestra fala da desconfianza tras o golpe militar, mesmo cara aos propios veciños, e da opresión contra as mulleres mediante malleiras e o rapado do cabelo. Unha atmosfera de medo que tamén aparece en Cardume coa decisión de abater en pleno día as contras e correr os ferrollos, así como a través do sentimento de indefensión das mulleres soas. Neste sentido, ambas obras sitúanse máis como novelas sobre os períodos de preguerra ou posguerra que sobre a guerra en si tal e como adoita entenderse. Ben é certo que a maior parte do material epistolar de NVS data dos anos 37 ao 39, mais por mor das particularidades estratéxicas ás que se viu sometida Galicia, os procesos narrados correspóndense cos dunha retagarda sen fronte militar, xa baixo control do réxime franquista, 


\section{Irene Pin Basanta}

elaborando as formas de represión que anticipan o transcurso da dura posguerra. Neste sentido, cómpre recordar que "en Galicia, al no haber frente, el conflicto gozó de una cierta invisibilidad que a menudo se interpretó como ausencia de violencia y sufrimiento" (Vilavedra, 2011b: 74). Con todo, o relato das diferentes formas de represión antes referidas dá conta dunha realidade marcada pola brutalidade e a anguria silandeira.

A gran forma de opresión de NVS é a incomunicación expresada pola correspondencia unidireccional de Sara Salgueiro. As cartas sen resposta supoñen ao cabo o fin da relación amorosa, arrefriada polo tempo, a distancia e a imposibilidade. Renunciando ao ideal desa fidelidade invencible da Pepita de La voz dormida, Sara decide casar con outro exiliado, Eduardo Souto, malia considerar a Moncho o grande amor da súa vida.

O diario de Moncho revela a outra cara da historia. Comeza o 18 de outubro do 36, tras ser trasladado do Frontón (Vigo) á Illa de San Simón. Urbano, arrestado o 15 de agosto, segue o mesmo percorrido, escribindo tamén os seus pensamentos. Ambos retratan a anguria en primeira persoa ante a incerteza tan próxima da morte, se ben Urbano o fai de maneira máis poética. O tío Moncho consegue librarse da morte, trasladado a Pontevedra na espera do xuízo que o condenará a anos de cadea. Así, retratará a posguerra desde unha atroz desesperanza: "Xa non debe quedar ninguén a quen matar, ninguén a quen encarcerar. Xa todo debe ser un inmenso cemiterio, sobre o que pasean feroces estes novos bárbaros" (Fernández Paz, 2002: 88). Urbano, porén, será executado, condenado por crer no "valor da ficción, a beleza e o sentido do teatro" (Vega, 2007: 191).

Se ambas obras inciden sobre a barbarie destes asasinatos, en Cardume matízase coa introdución da personaxe de Dámaso, que serve para explorar a ideoloxía falanxista e introducir a oposición entre os sublevados, aos que el mesmo representa, e o bando republicano, introducido por Urbano. Supón deste xeito unha retrato do clima de odio previo á guerra e da radicalización ideolóxica baixo a descrición do pensamento en "branco e negro", que se atribúe tanto a un como ao outro. Isto materialízase no episodio de boicot da obra de Urbano, que remata coa morte dun dos seus actores: o estaleiro Eudosio Riveiro. Os rapaces falanxistas actúan como heroes nunha misión que os sobrepasa: "axudar a sandar un corpo enfermo, cortar a infección, extirpar o membro gangrenado, se for preciso a golpe de machada" (Vega, 2007: 103). Deste xeito, Vega traslada o punto de vista reaccionario combinándoo co republicano, desde o que tamén se utiliza a macrometáfora da guerra. Así, Eudosio convértese en "soldado caído no embrión dunha batalla" (Vega, 2007: 109), pero Urbano sitúao no bando dos xustos, ao que el mesmo pertence tamén, manifestando o sentimento de deixar de ser un home para volverse parte dunha idea, dunha causa. 


\section{As sombras do Cardume: a guerra civil na memoria interxeracional}

Esta visión da Guerra Civil Española encaixa coa súa habitual denominación, xunto á II Guerra Mundial, como a última guerra romántica do século XX.

Alén das posturas máis comprometidas, Cardume retrata personaxes desvinculadas da política, mais non por iso necesariamente alleas ao conflito que as rodea. Malia o seu anterior desinterese nos mitins e manifestacións, a avoa admite ter opinión e, con ela, "unha parte por minúscula que fose de responsabilidade" (Vega, 2007: 156). Atrapada no bando equivocado, ninguén agarda nada dela, agás silencio e obediencia, pero intenta aínda así salvar ao seu curmán Urbano coa intervención do avó. El, aínda que non ve maldade nos condenados polo novo réxime,

non se significa, decide obedecer, calar e non pensar. Finalmente, contra a súa natureza, subornará inutilmente ao director da prisión para que libere a Urbano. Fasito, desde a emigración, permanecerá impasible ante a petición de axuda da irmá, desvinculándose dos acontecementos en contraste coa diáspora exiliada representada en NVS por Sara Salgueiro, que seguirá tendo moi presente o seu país.

\section{Silencio e lembranza}

As derradeiras páxinas do diario do tío Moncho están arrincadas, algo que Sara interpreta como produto da propia vontade de esquecer as palabras máis dolorosas. A infección de oído que collera na cadea remata por deixalo xordo e, unha vez libre, vólvese moi calado. A nai de Sara laméntase: “Deus, que metáfora tan terrible daqueles anos!”. O silencio é pois un aspecto central en NVS. A pesar de non ser contrarios á ideoloxía de Moncho, sobre a súa historia precipítase unha inmensa sombra, evidente na vontade da avoa por conservar pechado o seu cuarto, se ben manifesta certo desexo de homenaxear a seu irmán ao revelarse como a responsable de que Sara comparta nome coa namorada do tío Moncho. En contraposición, Rexina Vega (2007: 23) crea un universo enchoupado polas lembranzas, identificando as da guerra, iso si, por unha baixada de volume. Con todo, a ferida da contenda non está ausente: "Cando todo rematou aquela xeración fíxose vella, todos a un tempo, marcados coa carraxe ou a vergoña”.

A restauración do pasado vólvese en NVS un elemento de unidade familiar. A fixación da memoria é tamén un aspecto desenvolvido en Cardume, pero dáse directamente entre avoa e neta, pois a xeración intermedia está ausente por causa da emigración. Pola contra, a nai de Sara toma conciencia da lousa de silencio deitada involuntariamente sobre a memoria do tío, da que ela 


\section{Irene Pin Basanta}

mesma foi cómplice, e "asume unha postura que permite recompoñer un canal de transmisión dun pasado interrompido polos pais e agora retomado pola filla" (Agrelo Costas, 2015: 344). A súa denuncia esténdese á explicación que Sara recibira na escola sobre a guerra:

\footnotetext{
unha liorta entre irmáns, onde os dous bandos tiveran a mesma culpa; esa era a conclusión que o resumía todo. Lembro que calei e non che dixen nada, deixei que esa amarga mentira seguise estendéndose; ao cabo, que máis tiña o que pensases ti dunha etapa que xa quedaba tan lonxe. Hoxe vexo claro que aquel día lle dei unha labazada á memoria de meu tío, e á de todas as persoas que, coma el, un día soñaron un mundo diferente. Non ten sentido o rancor, ben o sei, pero aínda o ten menos o esquecemento e a mentira. Como se poden igualar as vítimas e os verdugos? Debes coñecer qué pasou aqueles anos para que nunca se repita, e tamén para honrar a memoria de tantos soños rotos (Fernández Paz, 2002: 103).
}

A nai representa a opinión do autor (Soto, 2008: 266) así como a súa xeración (Neira, 2012: 399), defendendo a necesidade de recuperación da memoria histórica que debe emprender a xeración da propia Sara e, consecuentemente, a do lector. Este discurso didáctico cuestiona o tratamento da guerra civil no ensino e, asemade, a vontade de reconciliación baseada nun exercicio de amnesia colectiva tal e como se levou a cabo na Transición. Así pois, o fío da memoria interxeneracional vai do tío Moncho a Sara, saltando as dúas mulleres que poderían ter sido depositarias: a nai e a avoa. Cada unha destas personaxes representa unha función diferente atendendo á xeración da que forman parte. Mamá Laura, como representante dos que viviron a contenda, evoca o medo e a desolación dun pasado traumático e doloroso que todos prefiren esquecer a través do silencio, aínda que manteña quizais certa vontade de lembranza ou homenaxe ao pórlle a Sara o nome da namorada do seu irmán, "mantendo vivo o recordo dunha historia de amor e dun tempo quebrados pola guerra” (Agrelo Costas, 2015: 344-345). A nai de Sara, representante da xeración intermedia, malia ser consciente da importancia do tema, eludiu a súa responsabilidade como transmisora: só a través de Sara é capaz de coñecer o pasado do seu tío. A nai define esta actitude cara ao pasado cunha metáfora facilmente accesible ao público adolescente: os restos dunha batalla fican baixo o xeo e a neve, nunha paisaxe de beleza enganosa, pois co desxeo primaveral os cadáveres volven quedar ao descuberto entre a lama, "revelando todo o horror que a neve sepultara" (Fernández Paz, 2002: 102).

Rexina Vega describe a guerra a través da imaxe da obra de teatro que nunca chegará a representarse, detida, transformada nun "símbolo maior da derrota, do silencio obrigado" (2007: 132). Porén, as relacións cos feitos pasados non están marcadas exclusivamente polo silencio e en Cardume son máis complexas. A narradora pregúntase polo pasado como garda do seu avó. Mataría? Supón que non, malia que el non llo confirmase nin llo desmentise nunca. Por outra 


\section{As sombras do Cardume: a guerra civil na memoria interxeracional}

banda, destaca a contraditoria admiración que a avoa sentirá en última instancia por Dámaso. Malia ser o responsábel da morte de Urbano, triunfa o seu sorriso de galán, a súa caste de gañador (Vega, 2007: 172), asociada á imaxe do heroe nacional difundida pola propaganda de filmes como Raza (Sáenz de Heredia, 1941). Así, a avoa conservará con orgullo o tapiz do Cristo de Xetsemaní, agasallo do que fora o seu primeiro amor.

Entendéndose a si mesma como unha xeración estragada pola posguerra, a nai deposita en Sara a responsabilidade de restaurar o pasado. De tal xeito, emprenden xuntas a viaxe á illa de San Simón para atopar o anel agochado por Moncho, co que poderá descansar en paz. A proximidade entre nai e filla, recorrente nas distintas imaxes proxectadas da figura materna na obra de Fernández Paz (Agrelo Costas, 2015: 565), acada o seu clímax cando ambas senten a presenza paranormal:

Foi coma se o tempo quedase suspendido e, por uns instantes, as paredes e a illa enteira desaparecesen da nosa vista. Nós soas, entre o mar e o ceo, rodeadas por aquela presencia invisible que nos envolvía.

¿Canto tempo estivemos así? Miña nai comentoume despois que, en tempo de reloxo, non máis de cinco minutos. Pero que a ela, o mesmo que a min, lle parecera unha eternidades (Fernández Paz, 2002: 164).

O proceso conxunto de reparación dos asuntos pendentes do tío Moncho dá paso a un final positivo e esperanzador que se manifesta tamén noutras narracións do autor que seguen a liña da recuperación da memoria, desde o "ciclo das sombra" ata Non hai noite tan longa e $A$ viaxe de Gagarín, onde os axentes dese rescate fican marcados de por vida (Agrelo Costas, 2015: 557). Asemade, a dimensión paranormal do relato, a través da presenza do tío que Sara percibe, sitúase nunha dimensión ambigua que o lector debe resolver. A este respecto, o propio Fernández Paz ten revelado que a recorrencia ao elemento fantástico na súa obra se debe á maior liberdade que este lle outorga para afrontar a realidade:

\footnotetext{
Creo que, de algún modo, esto me permite hablar con mayor libertad del mundo real, sin tener que sentirme limitado por un realismo estricto, que podríamos cuestionar desde muchos puntos de vista. Como dice Paco Martín, "no tengo nada claro dónde comienza la fantasía y dónde acaba la realidad”. De todos modos, siempre trato los elementos fantásticos con procedimientos narrativos realistas, una técnica en la que Kafka es el gran maestro (Peonza, 2003: 42)
}

Esta presenza, atribuída por Sara ás ánimas de mamá Laura ou do tío Moncho, simboliza para Vidal (2002: 37) a memoria viva que está desexando transmitirse. Máis alá da permanencia 


\section{Irene Pin Basanta}

dos mortos no mundo dos vivos (elemento moi propio da idiosincrasia galega), pode facerse dela unha lectura alegórica da necesidade por recuperar a memoria daqueles aos que lles foi arrebatada. Neste sentido, Fernández Paz crea un discurso sobre a Guerra Civil especialmente interesante para o público xuvenil, pois cuestiona a relación que as xeracións anteriores estableceron coa guerra outorgándolles aos seus lectores un papel activo. Como conclúe Soto (2008, 266): "Coñecer, comprender e non esquecer son as armas para loitar contra a desmemoria. A presenza sobrenatural acada finalmente o seu descanso cando a adolescente atopa o obxecto escondido na Illa e o coloca no dedo, símbolo de que a historia foi rescatada e salvada do terríbel esquecemento". A este respecto, non deixa de ser significativo que unha das modalidades nas que Roig Rechou divide o corpus temático sobre a guerra civil en Galicia se refira xustamente a "Sombras e descubertas", facendo de "a recuperación da memoria do pasado grazas á intervención de adolescentes que adoitan recorrer á axuda dalgún adulto para conseguir romper o silencio e dar a coñecer feitos que foron en contra das liberdades individuais e que castigaron formas de pensar diferentes" (Roig Rechou, 2008: 79). Existe, pois, unha reacción positiva enfocada na actitude das novas xeracións, capaces de desenterrar o pasado e empregalo para afianzar e fortalecer o seu propio presente.

A presenza do paranormal aparece en Cardume como orixe do relato, un deixarse posuír pola ouigha, mais tamén co espiritismo como práctica habitual na posguerra, nun aire cargado de mortos e de vivos que non poden esquecer nin aceptar. Nun episodio que transcorre en 1941, ao comunicarse con Urbano, a medium transmitirá a súa última vontade desoída: "queimádeo todo". Este desexo de eliminar o seu traballo procede dun sacrificio último por impedir que poida prexudicar a aqueles que intentaron axudarlle. A recuperación da memoria elaborada pola autora contravén esta vontade, restaurando o asasinato do seu antepasado a través dunha ficción na que palpita moito de realidade.

Atopámonos ante unha idea do paranormal que en ambos textos se asocia, insinuando, á memoria histórica da Guerra Civil como un asunto pendente. Presente en moitos outros relatos como fórmula para lidar tanto co esquecemento como cos conflitos nos resoltos, lémbrese que o sobrenatural aparece especialmente a través da figura infantil no cinema, como acontece por exemplo en El Laberinto del Fauno (Guillermo del Toro, 2006) ou, de maneira máis ambigua e vencellada á propia ollada da infancia, en El Espíritu de la Colmena (Víctor Erice, 1973). Esta tendencia non pode menos que porse en relación como unha estratexia que chama a atención sobre as porosidades da memoria sobre o discurso institucional da historia oficial. 


\section{Conclusións: cuestión de públicos}

Existen numerosos puntos de conexión entre Cardume e NVS, pero con notables diferenzas froito da súa adaptación ou concepción para diferentes lectores. Así, a importancia dos documentos, a recursividade de certos espazos ou a oposición entre idealismo e barbarie encarnada a través da represión aos intelectuais, repítense, se ben cunha menor densidade en favor do silencio e a necesidade de reparalo por parte de Fernández Paz, establecendo unha visión máis maníquea que, con todo, transmite unha mensaxe explícita sen caer na "prédica moralizante" (Agrelo Costas, 2015: 344). Igualmente, a común presenza do sobrenatural como un fondo indeterminado adquire máis peso no relato destinado a público xuvenil, probablemente procurando espertar o seu interese a través do misterio.

Un aspecto moi relevante en NVS é a lectura, unha paixón compartida pola familia da protagonista. A narradora emprega constantemente referencias literarias para describir a súa realidade. Máis alá da biblioteca galeguista que descobre no cuarto do tío Moncho, a literatura ten un papel predominante como vehículo de comunicación entre os amantes cos poemas de Cabanillas e Neruda. Ademais, a correspondencia de Sara Salgueiro aporta gran cantidade de datos sobre a vida política e intelectual da época, pero adaptados aos coñecementos dunha adolescente, evitando a saturación do lector. En Cardume, porén, se ben atopamos alusións a personaxes da cultura popular (Mary Poppins, Hansel e Gretel) existen outras moito máis especializadas: Mary Osborne, Heidi Lamarr, John Gilbert, a compañía Pino-Thuiler, a agrupación lírica Ortega... Roig e Soto (2008: 163-164) apuntan como Fernández Paz emprega os títulos que lle gustan para caracterizar mellor as súas personaxes, apropiándose da máxima de Borges "yo soy los libros que he leído”. Ademais, mediante a alusión a autores galegos preténdese reflectir ese renacemento cultural de Galicia que esvaeceu coa irrupción do conflito bélico do 36, non recoñecido pola historia oficial (Agrelo Costas, 2015: 340).

En NVS, o proceso de maduración da protagonista, anticipado desde o comezo, defínese a partir da descuberta do pasado, incidindo na importancia das orixes para comprendérmonos a identidade propia. Sara afirma no último parágrafo conservar o anel do seu tío, que lle lembra asemade o pasado e lle dá confianza cara ao futuro. Se ben a novela de Fernández Paz presenta un discurso sobre a recuperación da memoria sólido e ben articulado, a relación entre este e o proceso evolutivo da protagonista non parece tan evidente como acontece, por exemplo, en 


\section{Irene Pin Basanta}

Corredores de Sombra, onde as repercusións da descuberta sobre a protagonista son máis abruptas debido á súa vinculación cun pai afín á ideoloxía dos vencedores, condicionando para o resto da súa vida as relacións coa súa familia e, por extensión, os seus estudos e traballos. Con todo, Sara refírese a "acontecementos que me sacudirían de arriba a abaixo e me obrigarían a madurar de golpe, facendo aflorar no meu interior enerxías secretas que nin sequera imaxinara” (Fernández Paz, 2002: 11), dando conta da transcendencia que para ela ten esta experiencia.

O proceso de maduración tamén se observa na obra de Rexina Vega, pero de maneira moito máis esbozada, nunha narradora que se refire a si mesma de nena, medrando ao longo do libro. Así, por exemplo, admite que aos doce ou trece anos non imaxinaba que o seu avó tivese alternativa a intentar sobrevivir sen tomar partido. Este distanciamento da postura da súa adolescencia suxire unha perspectiva diferente sobre esta afirmación, mais sen achegar conclusións, deixando ocos abertos para a interpretación do lector. Por outra banda, Cardume non exclúe o universo sexual como parte da realidade cotiá. De tal xeito, descríbense de maneira explícita as diversas fazañas dos amigos gigolós, incluída a felación que Fasito lle fai a Dámaso (tratando os prexuízos contra a homosexualidade) ou o coito con Maruchi Campos. Aínda que en NVS se fai alusión aos encontros amorosos de Sara con Daniel, a obra mantense á marxe de tratar abertamente estes aspectos, cousa que Fernández Paz si fai en obras como Corredores de sombra (a condición homosexual do tío Carlos motiva a súa fuxida a Barcelona) ou Non hai noite tan longa (infidelidade de Gabriel).

As apreciación expresadas neste apartado inciden especialmente nas diferenzas de enfoque segundo as audiencias ás que os libros están dirixidos. Mentres Fernández Paz elabora un discurso comprometido cos esquecidos, procurando espertar no público adolescente o interese por recuperar a memoria sepultada da guerra e a posguerra, Cardume está escrito coa conciencia dunha ferida aberta, mais desprendido de maniqueísmo e vitimismo. Texto de poderosas imaxes e elevada carga poética, esixe unha lectura atenta para desentrañar a densidade que as palabras tecen nas súas capas, o que o fai pouco accesible para un lector adolescente medio. Porén, nas dúas obras, presente e pasado aparecen vencellados, constituíndo propostas interesantes para achegármonos á memoria interxeracional da Guerra Civil. Admitindo a necesidade aínda actual desta sorte de discursos sobre un conflito irresolto, cómpre non esquecer que

\footnotetext{
En tanto que discurso ficcional, la literatura gallega trabaja con memorias, no con la memoria, es decir, rescata y explora -explota- memorias parciales, marginadas, contestatarias (protestantes, anarquistas...) que de facto ponen de manifiesto la imposibilidad de elaborar una memoria única y la necesaria dimensión caleidoscópica de toda memoria colectiva" (Vilavedra, 2011b: 67-68).
} 
As sombras do Cardume: a guerra civil na memoria interxeracional

\section{Referencias bibliográficas}

AGRELO COSTAS, E. (2012). “A recuperación da memoria persoal e dun tempo: Non hai noite tan longa e $A$ viaxe de Gagarin, de Agustín Fernández Paz”. Boletín Galego de Literatura, 48, 15-28.

AGRELO COSTAS, E. (2015). Da institución escolar ao centro do canon: Agustín Fernández Paz. Tese doutoral. Santiago de Compostela. Universidade de Santiago de Compostela. Consultado o 5 de xuño de 2018, https://minerva.usc.es/xmlui/handle/10347/13822

BAZIN, A. (1990). ¿Qué es el cine?. Madrid: Rialp.

CASTRO DE PAZ, J. L. e Pena Pérez, J. J. (2005). Cine español. Otro trayecto histórico: Nuevos puntos de vista. Una aproximación sintética. Valencia: Ediciones de la Filmoteca.

FERNÁNDEZ PAZ, A. (2002). Noite de Voraces Sombras. Vigo: Edicións Xerais de Galicia.

FERNÁNDEZ PAZ, A. (2006). Corredores de Sombra. Vigo: Edicións Xerais de Galicia.

FRANCO, C. (2007, 11 de novembro). "Sempre quixen ser miliciana". La Voz de Galicia. $\begin{array}{llllll}\text { Consultado } & \text { o } & 5 & \text { de }\end{array}$ https://www.lavozdegalicia.es/noticia/cultura/2007/11/09/sempre-quixenmiliciana/0003 6303297.htm

HEMINGWAY, E. (1984). ForWhom the Bell Tolls. Granada: London.

HILlMAN, D. (2015) “Staging Early Modern Embodiment”. En Hillman D. e Maude, U. (Eds.). The Cambridge Companion to the Body in Literature (pp.41-57). New York: Cambridge University Press.

IGLESIAS, O. (2007, 10 de xuño). "Rexina Vega gana el Xerais con una obra contada por una nieta de la Guerra”. El País. Consultado o 7 de xuño de 2018, https://elpais.com/diario/2007/06/10/galicia/1181470700 850215.html

MARTÍN ROGERO, N. (2008). "Guerra civil y posguerra en la narrativa escrita en castellano”. En Roig Rechou, B.A., Domínguez, P.L. e Soto López, I. (Eds.). A guerra civil española na narrativa infantil e xuvenil (pp. 31-53). Vigo: Edicións Xerais de Galicia.

MARTÍNEZ, I. (2012). “Monteverde somos todas”. Tempos Novos, "Protexta”, 19, 10.

NEIRA RODRÍGUEZ, M. (2012). "La guerra civil española en la obra de Agustín Fernández Paz”. En Ramos, R. e Fernández Mosquera, A. (Eds.). Literatura Infantil y Juvenil y Diversidad Cultural/Literatura para a Infância e Juventude e Diversidade Cultural. (pp. 393-406). Vigo/Braga: ANILIJ/ELOS. CD-Rom/E-book. 


\section{Irene Pin Basanta}

O’BRIEN, R. (produtora) e LOACH, K. (director) (1995). Land and Freedom [cinta cinematográfica]. Coprodución Reino Unido / España / Alemaña: Parallax Pictures, Messidor Films, Road Movies Britte Produktionen, RTVE, Polygram Filmed Entertainment, Working Title Films.

PEONZA (2003). “Entrevistamos a Agustín Fernández Paz”. Peonza, 64, 40-50.

POUILlON, J. (1970). Tiempo y novela. Bos Aires: Paidós.

ROIG RECHOU, B-A. (2008). “A guerra civil na narrativa infantil e xuvenil galega: unha temática incompleta”. En Roig Rechou, B.A., Domínguez, P.L. e Soto López, I. (Eds.). A guerra civil española na narrativa infantil e xuvenil (pp. 69-104). Vigo: Edicións Xerais de Galicia.

ROIG RECHOU, B-A., RUZICKA KENFEL, V. e RAMOS, A.M. (Eds.) (2012). La Guerra Civil Española en la Narrativa Infantil y Juvenil. Porto (Portugal): Tropelias \& Companhia.

ROIG RECHOU, B-A e SOTO, I. (2008). "En Santiago de Compostela con Agustín Fernández Paz”. Boletín Galego de Literatura, 38, 161-178.

SOTO, I. (2008). "Literatura contra a desmemoria: unha lectura de Noite de voraces sombras, de Agustín Paz Andrade”. En Roig Rechou, B.A., Domínguez, P.L. e Soto López, I. (Eds.). A guerra civil española na narrativa infantil e xuvenil (pp. 251-270). Vigo: Edicións Xerais de Galicia.

VEGA, R. (2007). Cardume. Vigo: Edicións Xerais de Galicia.

VIDAL, C. (2002). “Agustín Fernández Paz. 'Non pararei ata que me lean tamén os adultos”. A Nosa Terra, "Guieiro cultural", 1.061, 37.

VILAVEDRA FERNÁNDEZ, D. (2011a). "Memoria y postmemoria: la elaboración literaria de la Guerra Civil en la narrativa gallega”. En Macciuci, R. (presidencia), II Congreso Internacional de Literatura e Cultura españolas contemporáneas. Congreso levado a cabo en La Plata, Arxentina.

VILAVEDRA FERNÁNDEZ, D. (2011b). “Guerra Civil y literatura gallega”. Revista Internacional de EstudiosVascos, 8, 62-77. 